\title{
Gender effects in laboratory public goods contribution*
}

\section{Do individuals put their money where their mouth is?}

\author{
Jamie Brown-Kruse \\ University of Colorado, Boulder, $\mathrm{CO}, \mathrm{USA}$
}

\section{David Hummels}

University of Michigan, Ann Arbor, MI, USA

Received July 1990, final version received June 1992

Recent work by Carol Gilligan posits that females are more cooperative and community minded than males. We use a series of laboratory experiments to test for gender effects in individual contribution rates to a pubiic good. Each member of a sane sex group of four was given the opportunity to contribute his/her endowment to a gruup iund fó a series of six rounds. We test for gender effects in contribution rates with a high and low group fund muitiplier and with and without preplay interaction. We found significant gender, group fund multiplier and period effects and interaction between the preplay communication and the multiplier. Counter to Gilligan's hypothesis, males contributed at higher rates than females.

\section{Introduction}

Recent works in Psychology and Political Science suggest that genderrelated behavioral differences exist. This runs counter to mainstream economic thought, which assumes that egoistic utility maximization defines rationality, and that decision processes are not differentiated with respect to gender.

The purpose of this study is to examine gender effects in a laboratory voluntary contribution/public goods framework. This group dilemma situation was chosen specifically because the individual's decision pits self interest

Correspondence to: Dr. Jamie Brown-Kruse, Department of Economics, University of Colorado at Boulder, Campus Box 256, Boulder, CO, USA.

*Funding for the experıments was provided by the University of Colorado through UROP (Undergraduate Research, Opportunity Program) and the Laboratory for Economics and Psychology. We would like to thank Robyn M. Dawes, Elizabeth Hoffman, Sheryi Ball, Peter Asch and an anonymous referee for valuable comments on earlier drafts. 
against group welfare. Though everyone in the group fares better if all contribute to the group fund, free riding yields a higher single period payoff.

In our experiments, all male and all female groups were given the opportunity to contribute an endowment to a group fund. The total contribution for the period was increased by a known multiplier and divided equally among the group regardless of individ al contribution decisions. The contribution decision and disbursement of the group fund was repeated for six rounds. Groups cycled through a high group fund multiplier and a low one or vice versa. The endpoint was not revealed to the subjects. Preplay interaction was induced in half of the groups by requiring they fill out a joint questionnaire. We found significantly higher contribution rates in male groups v. female groups. Further there were no statistically significant interaction effects between genủer and other treatment variables.

\section{Background}

Central to the question of public goods provision is the problem of the free rider. By definition, a public good is one enjoyed by all members of a community regardless of their contribution to that good. This situation invites free riding, in which a person gains from the public good without contributing to it. A public goods provision game sets up competing incentives: one is to contribute, thereby bentefiting the group as a whole; the other impulse is to free ride and benefit personally at the expense of the other group members.

There is a rich literature in experimental economics, experimental psychology, and game theory which seeks to characterize rational and/or human behavior in prisoner's dilemma/group dilemma situations. Fudenberg and Tirole (1991) describe the current state of the theory for this class of games. Dawes and Thaler (1988) give an overview of key experimental studies. They present evidence that human subjects in this decision framework exhibit 'anomalcis' cooperative behavior with $40 \%$ to $60 \%$ contribution rates.

Carol Gilligan (1982) suggests that humans exhibit two distinct behavioral constructs: contextualism and instrumentalism. Although she does not define either as male or female behavior, she finds empirical links between women and contextualism, and between men and instrumentalism. These empirical links have also been foun? in political behavior (Kathlene, 1989).

Contextualists stress intcrpersonal relatiounships, and equate morality with the fulfillment of obligations and avoidance of causing hurt to others. A contextualist would view free riding as harming others, damage to the social welfare, and/or non-fulfillment of obligations. Conversely, instrumentalists stress hierarchical relationships, and equate morality with justice, individual rights, and the 'Golden Rule' (Gilligan, 1982, 20). An instrumentalist would view free riding as a legal right. 
By Gilligan's arguments there would be a greaier tendency toward free riding in instrumentalists than in contextualists. Gilligan's empirical links to gender indicate that males are more likely to free ride. Gilligan indicates that the community-minded tendencies of women are limited, however. Under significant personal duress, survival instincts are expected to override altruism. This means that if we observe higher contribution rates in women, that contribution rate may still decline as rate of tradeoff between group benefit and personal benefit declines.

Based on Gilligan's postulates we have chosen group gender, the group fund multiplier and preplay interaction as treatment variables for our experiments. Gilligan's work drives the hypotheses that we will formulate and test in later sections.

The concept that group composition can be a determinant in a public goods provision game is not novel. There is a large body of literature describing Prisoners' Dilemma games in which gender is used as a treatment variable. The results of these studies are mixed. Several studies suggest that there are no gender-related differences in cooperation or defection [Lutzker (1961), Miller (1967), Fry (1967), Gailo, Funk and Levins (1969), Caldwell (1976), Dawes, McTavish and Shaklee (1977)]. In contrast, other articles suggest higher rates of cooperation by males [Rappoport and Chammah (1965), Bixenstine, Chambers and Wilson (1964), Komorita (1965), Kahn, Hottes and Davis (1971)], while still other articles suggest higher rates of cooperation by females [Vinacke (1959), Meux (1973), Grant and Sermat (1969), Aranoff and Tedeschi (1968), Jones, Gahagan and Tedeschi (1968)].

There are some notable problems in the approaches that were employed in many of the studies described above. First, because the payoffs in many of these games amounted to less than ten cents per round, loss of saliency could invalidate the results [Smith (1982)]. Second, some games did not look solely and specifically at gender as an explanatory variable in the experiment. In some cases, individuals were categorized prior to the experiment by subjective measures such as behavioral type or 'attractiveness' [Lutzker (1961), Kahn, Hottes and Davis (1971)], with populations altered to control for these variables. The experiments that we report were designed to adhere to the standards of good economic experimentation. Salient rewards were offered for subject decisions. The experimenter was truthful and no attempt was made to prescreen subjects. The may not provide the last word on differences due to our treatment variables, they do provide a foundation for future work.

\section{Methodology}

This study uses a four person public goods provision game to test for differences due to three treatment variables. We test for differences due to the 
Table 1

Description of group variable treatments.

\begin{tabular}{llll}
\hline $\begin{array}{l}\text { Experiment } \\
\text { ID no. }\end{array}$ & Gender & $\begin{array}{l}\text { Community/ } \\
\text { anonymity }\end{array}$ & $\begin{array}{l}\text { Group fund } \\
\text { multiplier sequence }\end{array}$ \\
\hline 1 & Male & Community & $2.0-1.2$ \\
2 & Male & Community & $2.0-1.2$ \\
3 & Male & Anonymity & $2.0-1.2$ \\
4 & Male & Anonymity & $2.0-1.2$ \\
5 & Male & Community & $1.2-2.0$ \\
6 & Male & Community & $1.2-2.0$ \\
7 & Male & Anonymity & $1.2-2.0$ \\
8 & Male & Anonymity & $1.2-2.0$ \\
9 & Female & Community & $2.0-1.2$ \\
10 & Female & Community & $2.0-1.2$ \\
11 & Frmale & Anonymity & $2.0-1.2$ \\
12 & Fenale & Anonymity & $2.0-1.2$ \\
13 & Female & Community & $1.2-2.0$ \\
14 & Female & Community & $1.2-2.0$ \\
15 & Female & Anonymity & $1.2-2.0$ \\
16 & Female & Anonymity & $1.2-2.0$ \\
\hline
\end{tabular}

gender composition of the group. Second the design addresses the issue of community by inducing interaction among members in half of the groups. Third, the high versus low conflict issue is tested by varying the group fund multiplier to make contribution more or less socially beneficial.

After instructions, the groups began a series of six rounds with each member making an all-or-nothing decision to contribute his/her endowment of $\$ 1$ to a group fund. Group contributions were totalled, multiplied by the group fund multiplier, then divided into four equal shares. Subjects were given running totals of their balances, group dividends, and payoff multipliers on a data slip and asked to signify their decision to invest in the next round.

The multiplier on the group fund was changed in the fourth round. Half of the groups started with a high multiplier and ended with a low multiplier, and the other half low, then high. Table 1 summarizes the experiments and treatments we employed.

The effect of gender is examined in like-sex groupings. Several studies indivate stronger sex-effects with this method [Rappoport and Chammah (1965), Aranoff et 2!. (1968), Jones et al. (1968)].

In the community $\mathrm{v}$. anonymity treatment, we controlled the nature of pre experiment communication. By filling out a required questionnaire, subjects in the community setting were encouraged to meet, talk, and learn about each other. Our goal was tc arouse a sense of membership in a group. Thus, group members were told tial they would remain in the same grour, for the entire session. At this time ir atid not know the nature of the experiment. 
Table 2

Payoff structure.

\begin{tabular}{llllll}
\hline & & \multicolumn{5}{c}{ Number of other contributors } \\
\cline { 3 - 6 } Contribution & Multiplier & 0 & 1 & 2 & 3 \\
\hline$\$ 1$ & 2.6 & 0.50 & 1.00 & 1.50 & 2.00 \\
$\$ 0$ & 2.0 & 1.00 & 1.50 & 2.00 & 2.50 \\
$\$ 1$ & 1.2 & 0.30 & 0.60 & 0.90 & 1.20 \\
\$0 & 1.2 & 1.00 & 1.30 & 1.60 & 1.90 \\
\hline
\end{tabular}

The induced community setting described above is compared with sessions in which no communication was allowed before the experiment. In fact, anonymity treatment subjects did not know the identity of other members in their group.

The anonymity groups were tested two groups at a time, with eight persons located randomly throughout the room. Care was taken so that no one would know which of the other seven subjects was in his/her group. As with the community groups, stibjects did know the gender of their fellow group members, and could not communicate with them once the experiment started.

By varying the group fund multiplier, we make contribution to the group more or less beneficial. In addition the chance of getting less from the group fund than contributed is rreater with the low multiplier. In the low multiplier ireatiment, a contributor will receive at least the initial contribution of $\$ 1$ back onlv if all other group members contribute. Contributors in the high nultiplier treatment need uni one other member to contribute in order to get at least the initial contribution back. Table 2 shows the payoff a subject can expect for a 0 or 1 dollar contribution given other group members' sontributions.

From a game theoretic perspective, the dominant strategy Nash equilibrium of the stage game is for all subjects to centribute \$0. Sibjects do not know the endpoint and we did not induce a fixed continuation probability in these experiments. Thus the rate at which subjects discount future payoffs is not controlled. However, we can find the critical discount factor for both group fund multipliers such that subjects are theoretically indifferent between a trigger strategy cooperative equilibrium and free-riding.

Suppose members choose to contribute to the group fund until one member defects, then contribute nothing thereafter. This cooperative equilibrium can be supporte in an infinitely repeated setting for some discount factor or in a repeated setting with unknown endpoint for some continuation probability. For a discount factor of 0.33 or more, a cooperative equilibrium can be supported for the high multiplier. The low multiplier requires a 
Table 3

Summary of mean contribution rates.

\begin{tabular}{llll}
\hline & All subjects & Male subjects & Female subjects \\
\hline Entire study & $62.6^{\circ}$ & $67.7 \%$ & $56.3 \%$ \\
Community & $66 . \%$ & $76.0 \%$ & $57.3 \%$ \\
Anonymous & $57.3 \%$ & $59.4 \%$ & $55.2 \%$ \\
Multiplier & & & \\
High & $70.8 \%$ & $75.0 \%$ & $66.7 \%$ \\
Low & $53.1 \%$ & $60.4 \%$ & $45.8 \%$ \\
Period & $82.8 \%$ & $93.8 \%$ & $71.9 \%$ \\
1 & $73.4 \%$ & $78 . \%$ & $68.8 \%$ \\
2 & $64.1 \%$ & $68.8 \%$ & $59.4 \%$ \\
3 & $59.4 \%$ & $62.5 \%$ & $56.3 \%$ \\
4 & $48.4 \%$ & $56.3 \%$ & $406 \%$ \\
5 & $43.8 \%$ & $46.9 \%$ & $40.6 \%$ \\
6 & $87.5 \%$ & $93.8 \%$ & \\
First period comparisons & $91.3 \%$ \\
Community & $88.1 \%$ & $62.5 \%$ \\
Anonymous & $78.1 \%$ & $93.8 \%$ & $68.8 \%$ \\
Multiplier & $81.4 \%$ & $93.8 \%$ & $75.0 \%$ \\
High & $84 \%$ & $93.8 \%$ & \\
Low & $84.4 \%$ & & \\
\hline
\end{tabular}

discount factor of 0.77 or more to support a trigger strategy equilibriuni like the one described. The set of discount factors that will support cooperation in a repeated setting is larger for the high multiolier. Therefore wie expect a higher contribution rate in high multiplier foriods.

The subject sample was drawn from undergraduate economics courses. There were 64 subjects, divided into 16 groups of 4 persons. The experiment was denominated in U.S. dollars. After the experiment was completed, subjects were paid and escorted individually from the room. The average payment per subject was $\$ 14.50$. Each session took about 60 minutes, including check in, instructions, decisions, and subject payments.

\section{Results}

There were a total of 96 rounds (16 groups $\times 6$ rounds per group) described by the number of individuals $(0-4)$ contributing in that round. These rounds were pooled by gender, by the group fund multiplier, by community/anonymity, and sy the number of the round. Table 3 contains a summary of the mean contribution rate for different partitions of the group.

Figs. 1 through 4 also summarize the results. Fig. 1 shows the first period mean contribution rate by men and women under the four treatments. The contribution rates for community $v$. anonymity provide some evidence that womeri do respond to the community setting. In the first period, subjects have no history of past responses by other group members. If there is any 


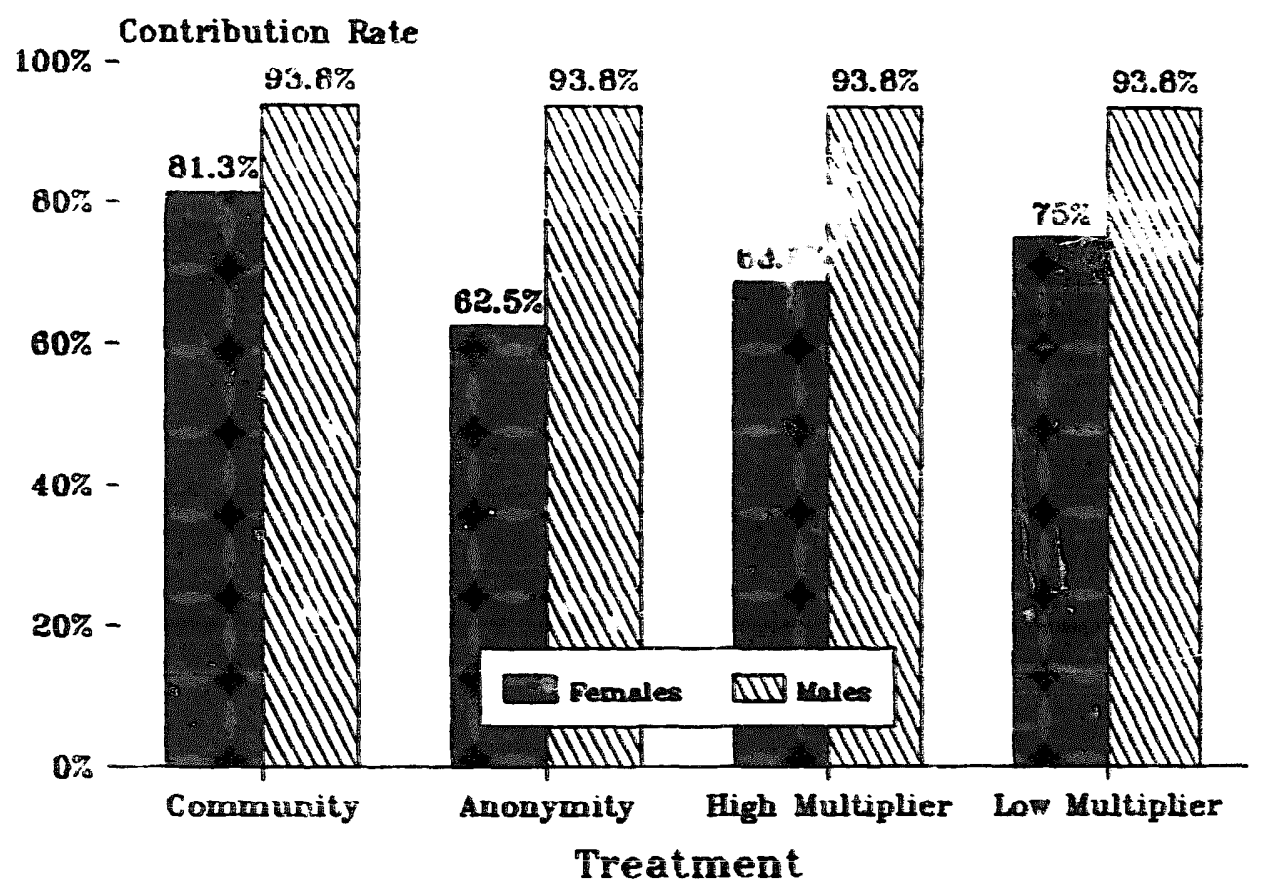

Fig. 1

response to the cooperative effort to fill out the questionnaire, it is logical to expect the strongest effect in the first period contribution. Interestingly, the mean male contribution rate across all treatments was $93.8 \%$ in the first period. The initial strategy chosen by men does not appear to be affected by our treatments. An analysis of variance (ANOVA) using the first period contributions reveals that we can reject the hypothesis of like mean contribution rates between males and females $(F=5.006, \alpha=0.05)$. However, we cannot reject the hypothesis of equal means beiween community/ anonymity and high/low multipliers.

Fig. 2 contains the mean curitribution rates for men and women by treatment for the whole session. The multiplier becomes more important as a determinant of contribution rate after the first period. One possible explanation is that the subjective expectation that the experiment will continue declines making contribution in the low multiplier case less likely to yield sufficient future returns.

An ANOVA was conducted using contribution rates from all periods. In all cases, the null hypothesis is that the means are equal, and the alternative hypothesis is that the means are not equal. We find significant differences in means due to gender $(F=4.00, \alpha=0.05)$, period $(F=3.67, \alpha=0.01)$, and group fund multiplier $(F=7.11, \alpha=0.01)$. There is a significant interaction effect for the treatments multiplier/community at alpha equal to 0.10 . It is also 
$100 \%$

Contribution Rate

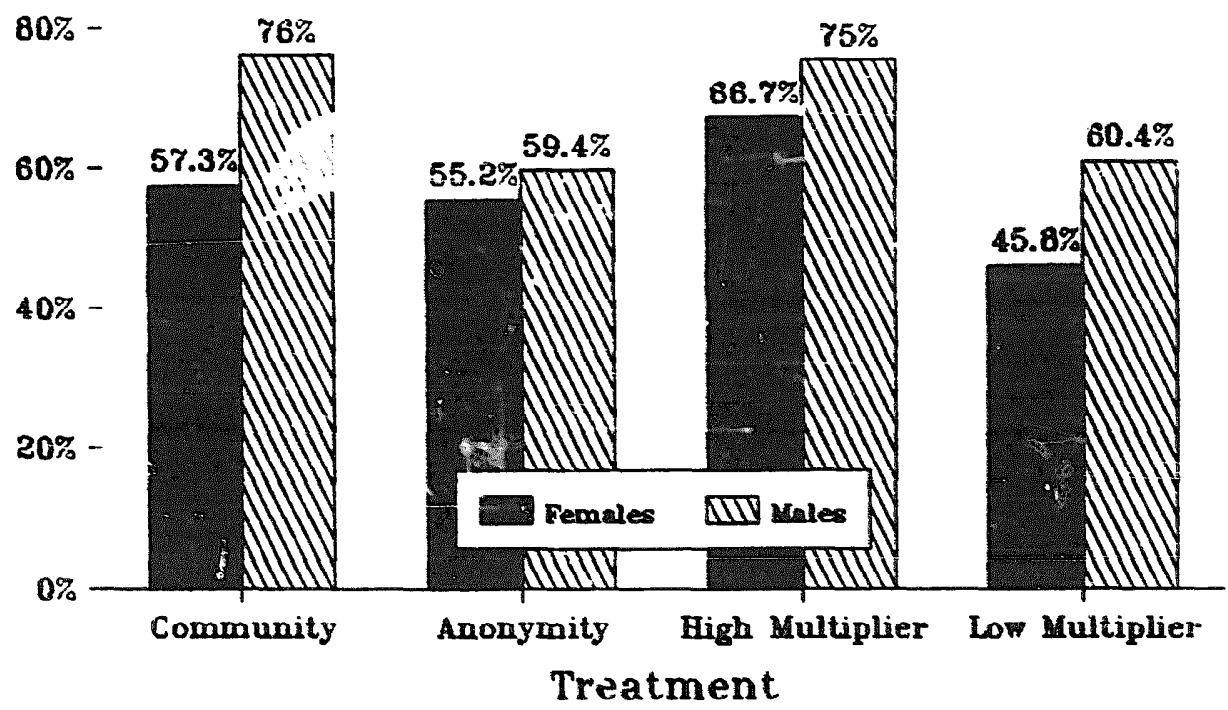

Fig ?

important to note that we were unable to reject the null hypothesis for the interaction of any other variables. Thus, there were no significant differences in the way that men and women responded to the community or multiplier treatments, nor in the way they contributed by period. The mean contribution rate declined over time for both males and females as illustrated in fig. 3 .

Fig. 4 classifies subjects by the number of periods that they chose to contribute. The frequencies are nearly the same except at the extremes. We define pure cooperators as those that contributed every period. Pure freeriders never contributed to the group fund. Of the 32 male subjects, there were 8 pure contributors and no pure free-riders. There were 4 pure contributors and 2 pure free-riders in the female cohort.

\section{Discussion}

The existence of differences according to the period of the contribution is consistent with previous wo: $\mathrm{k}$ which predicts decreasing contributions as the number of iterations increases [Isaac, McCue and Plott (1985), Dawes and Thaler (1988)]. Contriuutions decline monotonically from a first round mean of $82.8 \%$ to a sixth round mean of $43.8 \%$. The significant difference in the mean contribution rates between the multipliers is consistent with earlier work in this regard [Isaac, Walker and Thomas (1984)]. We saiw no interactive effects between the multiplier and gender. Our original prediction 


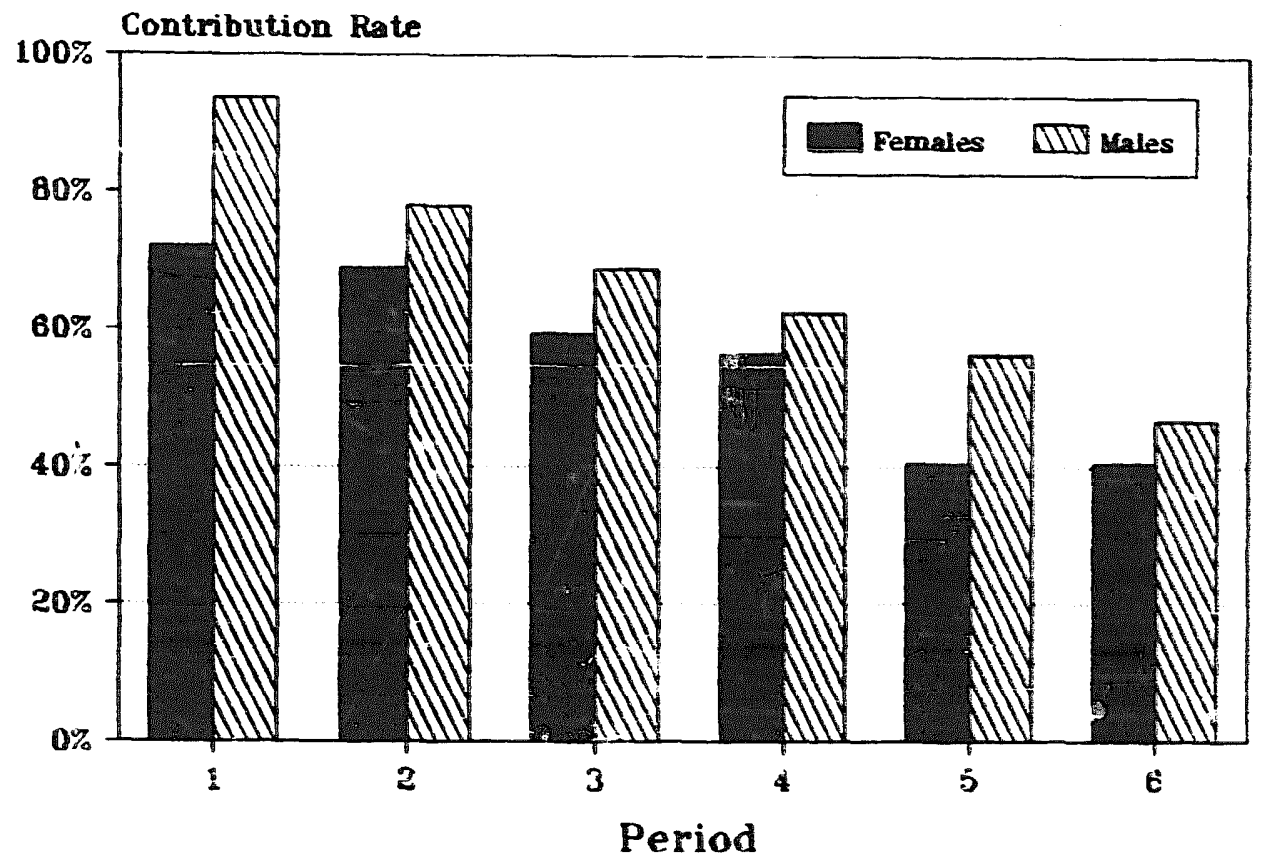

Fig. 3

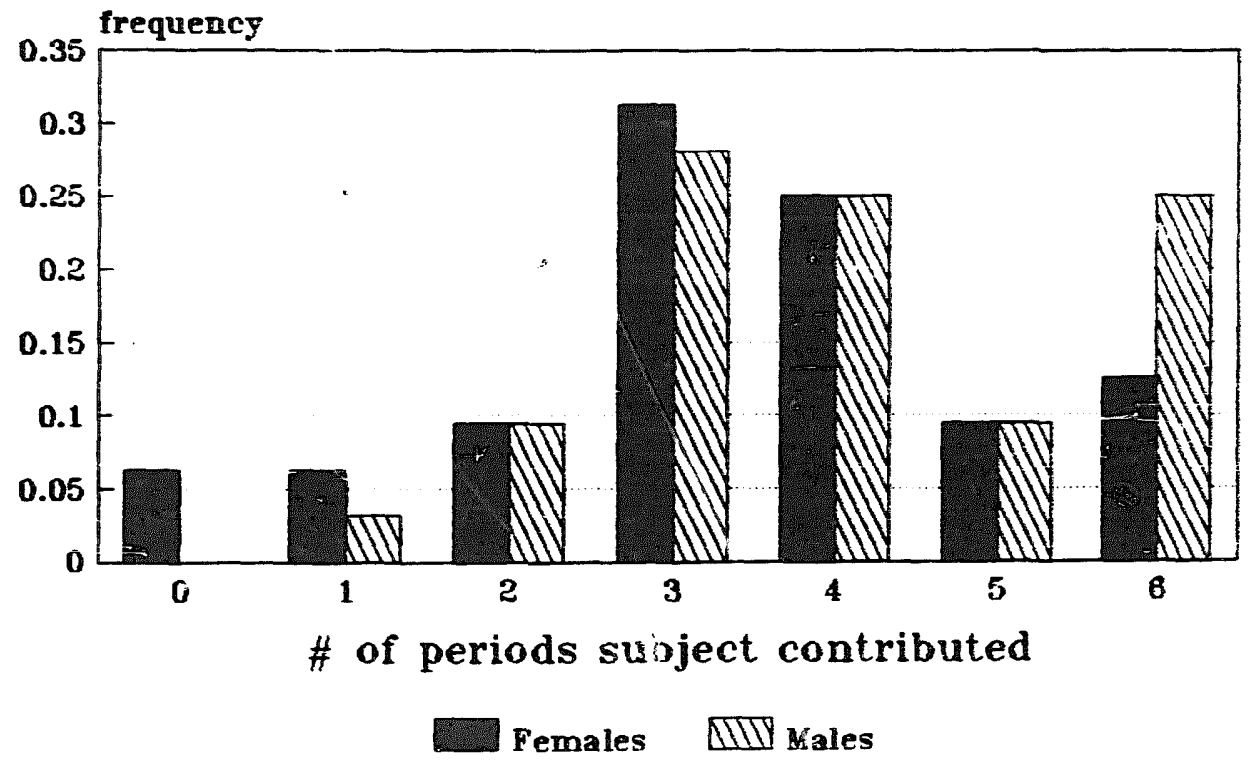

Fig. 4 
was that females would be more strongly affected by changes in the trade off between personal and social benefit. While simple averages show that females contributed at lower rates in the low multiplier treatment, the interaction effect was not statistically significant.

Differences in contribution rates according to the community setting are not statistically significant. This is consistent with the irrelevant communication condition in Dawes, McTavish and Shaklee (1977). There were no interactive effects between community and period or between community and gender. This result does not support Gilligan's theory that predicts females to be especially sensitive to the interpersonal nature of the community groups, resulting in higher contribution rates. There is some support for Gilligan's postulate in the first period means. However, males appear more responsive to community when we consider all periods. Though not statistically significant for either case.

One possibility is that the subject interaction facilitated by the preexperiment questionnaire failed to arouse true feelings of community in the groups. This analysis is somewhat contradicted by the existence of a statistically significant interactive effect between community and the multiplier. When the multiplier was high, contribution rates did not depend on the community treatment. However, when the multiplier was low, contribution rates depended strongly on the community treatment.

Finally, we look at the significant gender differences in contribution rates. Contrary to predictions, males contributed at higher rates than did women. There were no significant interactive effects between gender and other variables.

We might explain this result in two ways. The first looks at male cooperation, rather than female altruism. Some psychological theorists, notably Lever (1976), Mead (1934) and Piaget (1932), suggest that some gender-related personality differences are the result of how young boys and girls play. Boys are more likely to play team games, resulting in a more highly developed sense of cooperation and an increased ability to resoive disputes.

This school of thought posits that men cooperate better than women simply because they have more practice at it. The ideas that males are better abie to arrive at cooperative strategies is echoed in experimental work by Vinacke (1959), Kahn et al. (1971) and Komorita (1965).

A final explanation for our results goes back to the original studies conducted by Gilligan who cites gender-related behavioral differences based on empirical studies of how men and women talk about themselves and others. She suggests that this technique gives insight into the way men and women behave.

In our study, the subjects did not complete a formal post-experiment questionnaire. However, a number of the subjects made comments to the 
experiment monitor before and after the sessions. Many of these comments closely resemble the dialogues reported by Gilligan, yet the subjects' remarks match neither their actions nor her behavioral constructs.

For example, one female subject, upon being told that she would receive an equal dividend from the group fund even if she did lot contribute to it, replied, 'But that would be selfish!' Yet, in four of the six ensuing rounds, she failed to contribute.

One male, commenting on the experiment, said, "I would bave screived these guys over if I thought I could have gotten away with it'. However, he contributed in all six rounds. Another male explained his contribution in five of the six rounds by saying, 'I was only setting them up'.

Two females who later guessed that the experiment was testing genderrelated contribution rates predicted that female contributions would easily exceed that of males. Why? 'I just think women are more altruistic'. Between them, they contributed in only four of twelve rounds.

Again, using Gilligan's method of analysis, these various comments suggest that contribution rates for females should have been higher. Our results suggest two possibilities. Perhaps listening to how individuals talk about themselves and others does not give a true indication as to how they will act. Another possibility is the proposition that something intrinsic to economic decision-making inhibits altruism, the concern for others at personal expense. In either case, this study indicates that individuals apparently fail to put their money where their mouth is.

\section{Appendix A. Instructions}

You are about to take part in an experiment in economic decision making. You will be asked to make certain decisions during the course of the experiment Depending on the decisions you make, you will have the chance to make a considerable amount of money.

In the experiment you will be part of a four person group. As a group member, you will have several opportunities to invest money in a group fund. The group fund pays dividends to all members of the group after the investment decisions are made.

At the beginning of each of the investment opportunities, you will be handed a slip of paper. On this slip of paper will be information concerning the group fund. It will tell you the amount of the group fund dividend you received from the last round, how much money you have made in total throughout the experiment, and an amount (your endowment) that you can either keep or invest in the group fund during the next round. You may only choose to invest all or none of your endowment. You will mark this choice on the slip of paper and hand it back to the monitor.

The amount of the dividend paid to all group members is determined as 
follows: Group member contributions are added together. This sum is then multiplied by an investment multiplier, which represents the return on the group fund. (You will be told what the multiplier is before each round). Each group member then receives one-fourth of the multiplied total. (For example: A total of $\$ 12$ is contributed by the group members. The investment multiplier is 2 . After nultiplication, the group fund is worth $\$ 24$. This is divided by four, and each group member receives \$6).

At no time during the experiment may you conımunicate, either verbally or otherwise, with any member of your group. At the end of the experiment. you will be escorted individually from the room and paid $\$ 5$ plus the amoint you earned during the experiment. The payment wili be in cash.

The monitor will only be able to give clarifying answers to questions about these instructions before the experiment begins. Please reread the instructions carefully to ensure that you understand them. If you do not, please raise your hand and the monitor will assist you.

\section{Appendix B: Fre-experiment questionnaire}

Attention Group Members: While you are wa.ting for the experiment to begin, please work with the members of your group to fill out the information on this sheet.

Majors and other academic interests of group members:

1.

2.

3.

4.

Favorite athletic activity

Favorite flavor ice cream

1.

2.

1.

3.

2.

4.

3.

4.

Best book read lately 1.

Best movie seen lately

2.

3.

1.

2.

3.

4.

4.

Hobbies and special interests of group members:

1.

2.

3.

4. 


\section{References}

Aranoff, Daniel and James Tedeschi, 1968, Original stakes and behavior in the prisoner's dilemma game, Psychonomic Science 12, 79-80.

Bixenstine, V.E., Norman Chambers and K.V. Wilson, 1964, Effect of asymmetry in payof on behavior in a two-person non-zero-sum game, Journal of Cinflict Resolution 8: 151-159.

Dawes, Robyn M, Jeanne McTavish and Harriet Shaklee, 1977, Behavior, communication and assumptions about other people's behavior in a commons dilemma situation, Journal of Personality and Social Psychology 35, 1-11.

Dawes, Robyn M. and Richard H. Thaler, 1988, Anomalies: Cooperation, Journal of Economic Perspectives 2, 187-197.

Caldweht, Michel D., 1976, Communication and sex effects in a five-person prisoner's dilemma game', Journal of Personality and Social Psychology 33, 273-280.

Fry, C.L., 1967, A developmental examination of performance in a tacit coordination game situation, Journal of Personality and Social Psychology 5, 277-281.

Fudenberg, Drew and Jean Tirole, 1991, Game theory (MIT Press, Cambridge).

Gallo, P.W., S.G. Funk and J.R. Levine, 1969, Reward size, method of presentation and number of alternative in a prisoner's dilemma game, Journal of Personality and Social Psychology 13, 239-244.

Giligan, Carol, 1982, In a different voice, psychological theory and women's development (Harvard University Press. Cambridge. MA).

Grant, Malcolm and Vello Sermat, 1969, Status and sex of other as determinants of behavior in a mixed-motive game, Journal of Personality and Sociai Psychology 12, 151-157.

Isaac, R. Mark, Kenneth McCue and Charles R. Plot, 1985, Public goods provision in an experimental environment, Journal of Public Economics 26, Feb, 51-74.

Jones, B., M. Steele, J. Gahagan and J. Tedeschi, 1968, Matrix values and cooperative behavior in the prisoners' dilemma game, Journal of Personality and Social Psychology 8, 148-153.

Kahn, Arnold, Joe Hottes and William Davis, 1971, Cooperation and optimal responding in the prisoner's dilemma game: Effects of sex and physical attractiveness, Journal of Personality and Social Psychology 17, 267-279.

Kathlene, Lyn, 1989, Uncovering the political imparts of gender. An exploratory study, Western Political Quarterly 42, June.

Kim, Oliver and Mark Walker, 1984, The free rider problem: Experimental evidence, Public Choice 43, 3-24.

Komorita S.S., 1965, Cooperative choice in a prisoners dilemma game, Journal of Personality and Social Psychology 2, 741-745.

Lever, Janet, 1976, Sex differences in the games children play, Social Problems 23, 478-487.

Lutzker, Daniel R., 1961, Sex role, cooperation and competition in a two-person, non-zero sum game, Journal of Conflict Resolution 5, 366-368.

Marwell, Gerald and Ruth Ames, 1981, Economists free ride, does anyone else?, Journal of Public Economics 15, June, 295-310.

McNeel, S.P., C.G. McClintock and J.M. Nuttin, 1972, Effects of sex role in a two-person mixed-motive game, Journal of Personality and Social Psychology 24, 372-380.

Mead, George Herbert, 1934, Mind, self, and society (University of Chicago Press, Chicago, IL).

Meux, E.P., 1973, Concern for the common good in an N-person game, Journal of Personality and Social Psychology 28, 414-418.

Miller, R.R., 1967, No play: A means of conflict resolution, Journal of Personality and Social Psychology 6, 15-156.

Piaget, Jean, 1932, The moral judgment of the child (The Free Press, New York).

Rappoport, A. and A.M. Chammah, 1965, Sex differences in factors contributing to the level of cooperation in a prisoner's dilemma game, Journal of Personality and Social Psychology 2, 831-838.

Vinacke, W.E., 1959, Sex roles in a three-person game, Sociometry 22, 343-360. 